\title{
DESKRIPSI HEMATOLOGI KELELAWAR DI GUNUNG TANGKOKO BERDASARKAN PEMERIKSAAN DARAH LENGKAP
}

\author{
Arie J. Saimima ${ }^{1)}$, Edwin de Queljoe ${ }^{1)}$, Hanry J. Lengkong1) \\ 1) Jurusan Biologi FMIPA UNSRAT Manado, 95115
}

\begin{abstract}
This study aimed to describe the hematological data of several bat species netted on Mount Tangkoko based on a complete blood examination. Purposive Random Sampling method was used for field sampling, Mistnet method was used for bats sampling and Screening Test method was used for hematological examination. Blood was examined using the Abx Micros 60 Hiruba Medical machine. The examined blood components were erythrocytes, leukocytes, haemoglobin, haematocrit, and platelets/thrombocytes. The examination results showed that each blood component had different amount compared to humans, some other mammals with relativity in size and some other birds. The highest leukocyte count was found in T. nigrescens which was $28.00 \pm 19.04 \times 103 / \mathrm{mm}^{3}$. The highest erythrocyte count was found in T. nigrescens which was $13.45 \pm 1.52 \times 106 / \mathrm{mm}^{3}$. The highest haemoglobin and haematocrit count were found in $R$. amplexicaudatus which were $19.70 \pm 1.89 \mathrm{~g} / \mathrm{dl}$ and $65.70 \pm 5.65 \%$. The highest platelet/thrombocyte count was found in T. nigrescens which was $975.2 \pm 239.03 \times 103 / \mathrm{mm}^{3}$.
\end{abstract}

Keywords: Bats, Mount Tangkoko, Erythrocytes, Leukocytes, Haemoglobin, Haematocrit, Platelets

\begin{abstract}
ABSTRAK
Penelitian ini bertujuan untuk mendeskripsikan data hematologi beberapa spesies kelelawar yang terjaring di Gunung Tangkoko berdasarkan pemeriksaan darah lengkap. Sampling lokasi menggunakan metode Purposive Random Sampling, penangkapan kelelawar menggunakan metode Mistnet dan pemeriksaan hematologi menggunakan metode Screening Test. Darah diperiksa menggunakan mesin Abx Micros 60 Hiruba Medical. Hasil menunjukan lima komponen darah yaitu eritrosit, leukosit, hemoglobin, hematokrit, dan platelet/trombosit masing-masing memiliki perbedaan dengan manusia dan beberapa spesies mamalia lain dengan ukuran yang relatif sama serta beberapa spesies burung sebagai pembanding. Nilai leukosit tertinggi terdapat pada spesies T. nigrescens yaitu 28,00 $\pm 19,04 \times$ $10^{3} / \mathrm{mm}^{3}$. Nilai eritrosit tertinggi terdapat pada spesies T. nigrescens yaitu $13,45 \pm 1,52 \times 10^{6} / \mathrm{mm}^{3}$. Nilai hemoglobin dan hematokrit tertinggi terdapat pada spesies $R$. amplexicaudatus yaitu masingmasing 19,70 $\pm 1,89 \mathrm{~g} / \mathrm{dl}$ dan $65,70 \pm 5,65 \%$. Nilai platelet/trombosit tertinggi terdapat pada spesies $T$. nigrescens yaitu $975,2 \pm 239,03 \times 10^{3} / \mathrm{mm}^{3}$.
\end{abstract}

Kata kunci : Kelelawar, Gunung Tangkoko, Leukosit, Eritrosit, Hemoglobin, Hematokrit, Leukosit 


\section{PENDAHULUAN}

Kelelawar merupakan mamalia yang mampu terbang secara aktif dengan menggunakan sayap. Di Indonesia kelompok kelelawar terbagi menjadi dua sub ordo berdasarkan jenis makanannya yaitu, Megachiroptera (pemakan buah-buahan) dan Microchiroptera (pemakan serangga). Spesies kelelawar yang ada di Indonesia sekitar 230 spesies dan sebagian besarnya merupakan kelelawar pemakan serangga sebanyak 152 spesies (Suyanto, 2001).

Gunung Tangkoko berada di dalam Cagar Alam Gunung Duasudara yang terletak di ujung timur laut semenanjung utara Pulau Sulawesi dan masuk dalam administrasi Kota Bitung dengan ketinggian $1.108 \mathrm{~m}$ dpl (Wangko et al., 2000). Kawasan Cagar

Alam Gunung Duasudara kaya akan spesies-spesies burung Sulawesi dan mamalia terutama primata, Kawasan ini merupakan kawasan dengan spesies-spesies endemik tertinggi di Sulawesi yang menjadi kawasan konservasi (Lee et al., 2001). Kelompok mamalia lain yang banyak ditemukan di cagar alam ini yaitu kelelawar.

Penelitian mengenai hematologi penting untuk dilakukan karena pemeriksaan hematologi hewan dapat digunakan dalam menggambarkan status gizi, kondisi stres yang dialami oleh hewan (McMichael et al., 2015; Hossain et al., 2013), menentukan status konservasi dan manajemen populasi (Hall et al., 2014). Melihat Gunung Tangkoko sebagai wilayah konservasi sekaligus tujuan ekopariwisata, penelitian mengenai hematologi kelelawar belum pernah dilakukan di wilayah tersebut, sehingga tidak ada informasi mengenai hematologi kelelawar yang hidup di Gunung Tangkoko.
Pemeriksaan hematologi dapat berupa pemeriksaan darah lengkap (nilai hemoglobin, hematokrit, eritrosit, leukosit, dan trombosit) ataupun pemeriksaan kimia darah. Pemeriksaan darah lengkap bertujuan untuk memeriksa komponen darah agar diketahui apakah suatu kondisi hewan dapat dikatakan normal atau abnormal (Guyton dan Hall, 2008).

Pemeriksaan darah lengkap dapat dilakukan secara manual ataupun menggunakan alat bantu (mesin). Pemeriksaan darah secara manual memiliki keterbatasan antara lain waktu yang diperlukan untuk sekali pemeriksaan cukup lama, sehingga memungkinkan darah untuk terjadi koagulasi dan hasil pembacaan yang sangat bergantung pada manusia sehingga resiko human error cukup tinggi. Sedangkan kelebihan yang didapatkan dengan menggunakan alat bantu ialah hasil yang diperoleh bisa didapatkan dengan cepat, lebih efesien saat digunakan dan memperkecil resiko human error.

Berdasarkan informasi diatas belum terdapat data penelitian mengenai hematologi kelelawar yang hidup di Cagar Alam Gunung Duasudara khususnya Gunung Tangkoko, maka dari itu perlu dilakukan penelitian mengenai hematologi kelelawar yang ada di Gunung Tangkoko.

\section{METODOLOGI PENELITIAN}

Penelitian ini dilaksanakan pada bulan Maret 2019 sampai dengan bulan April 2019. Penentuan lokasi menggunakan metode purposif random sampling, penangkapan menggunakan metode mistnet (Lengkong, 2017), dan pemeriksaan hematologi menggunakan metode screening test (Kementrian Kesehatan RI, 2011). Mistnet yang digunakan yaitu ukuran 1 
meter dan 3 meter yang dipasang di antara dua batang pohon. Kelelawar dibius dengan klorofom sebanyak $0,5 \mathrm{ml}$ dan diambil darahnya sebanyak $0,2-1,5 \mathrm{ml}$. Darah diperiksa di Laboratorium Klinik Prokita Malalayang, Manado menggunakan mesin Abx Mikros 60 Hiruba Medical.

Identifikasi kelelawar menggunakan buku panduan lapangan oleh Suyanto (2001). Data hasil pemeriksaan hematologi yang digunakan yaitu; nilai hematokrit, hemoglobin, eritrosit, leukosit dan trombosit disusun secara deskriptif.

\section{HASIL DAN PEMBAHASAN}

Sebanyak 20 individu dari empat spesies berbeda dijadikan sampel dalam penelitian ini, semua sampel berasal dari satu famili yang sama yaitu Famili Pteropodidea. Spesies kelelawar yang berhasil terjaring dan diperiksa komponen darahnya yaitu; Rousettus amplexicaudatus, Rousettus celebensis, Thoopterus nigrescens, dan Cynopterus luzoniensis. Sebanyak lima individu dari setiap spesies diambil sebagai sampel untuk diperiksa data hematologinya. Morfologi empat spesies kelelawar dapat dilihat pada gambar 1 .

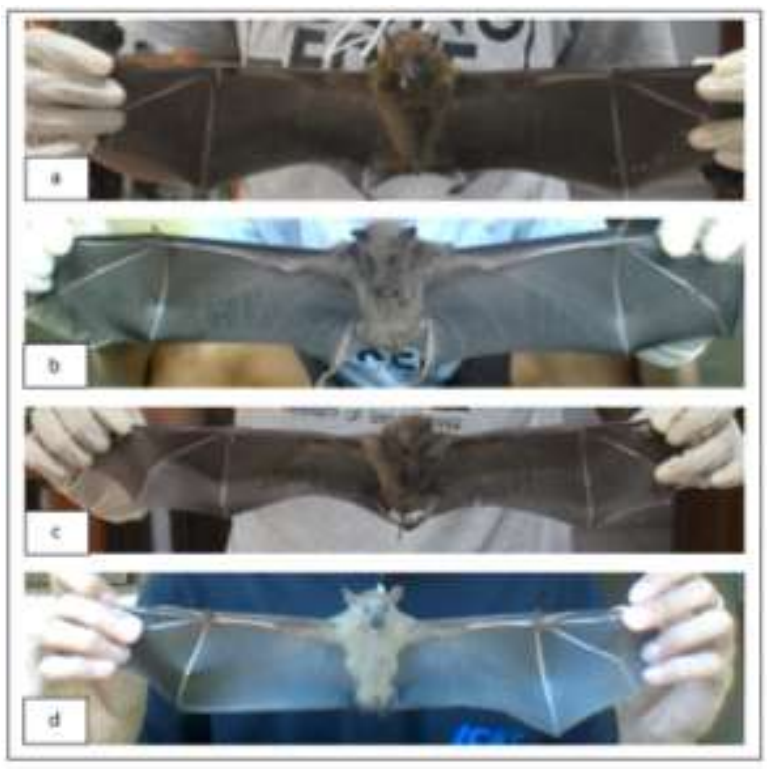

Gambar 1. Morfologi R. amplexicaudatus (a), $R$. celebensis (b), T. nigrescens (c), C. luzoniensis (d)

\section{Leukosit}

Nilai rata-rata leukosit spesies $R$. amplexicaudatus merupakan yang terendah sedangkan spesies $T$. nigrescens merupakan yang tertinggi. Nilai leukosit spesies $R$. amplexicaudatus memiliki nilai rataan \pm SD $9,5 \pm 4,43 \times 10^{3} / \mathrm{mm}^{3}, R$. celebensis $9,66 \pm$ $5,71 \times 10^{3} / \mathrm{mm}^{3}, T$. nigrescens $28,00 \pm 19,04$ $\times 10^{3} / \mathrm{mm}^{3}$, dan $C$. luzoniensis 16,24 $\pm 9,06$ $\times 10^{3} / \mathrm{mm}^{3}$ (Gambar 2).

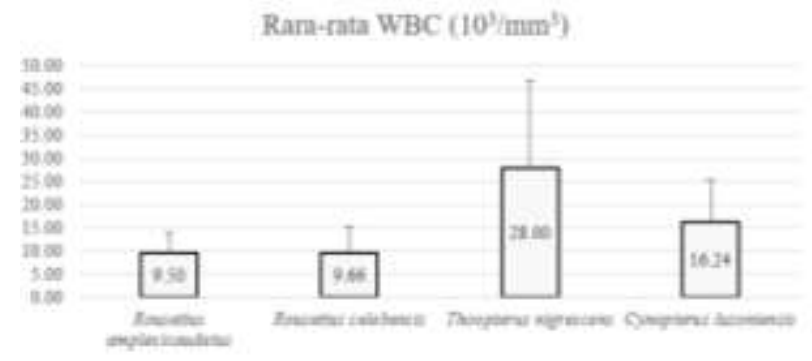

Gambar 2. Rata-rata nilai leukosit empat spesies kelelawar di Gunung Tangkoko

Nilai leukosit ini memiliki perbedaan dengan spesies mamalia lain. Jika 
dibandingkan dengan nilai leukosit manusia berdasarkan rentang nilai bacaan leukosit tempat pemeriksaan darah yaitu 3,6 - $11 \times$ $10^{3} / \mathrm{mm}^{3}$, spesies $T$. nigrescens dan $C$. luzoniensis berada diatas nilai bacaan leukosit manusia, sedangkan spesies $R$. amplexicaudatus dan $R$. celebensis berada pada nilai bacaan leukosit manusia. Jumlah leukosit yang diperoleh jika dibandingankan dengan kelelawar lain seperti Pteropus vampyrus 12,23 $\pm 7,61 \times 10^{3} / \mu \mathrm{L}$ (Cahyadi et al., 2018), spesies $R$. amplexicaudatus dan $R$. celebensis memiliki nilai leukosit yang rendah sedangkan spesies $T$. nigrescens dan C. luzoniensis nilainya lebih tinggi. Nilai leukosit dari empat spesies kelelawar ini jika dibandingkan dengan hewan yang ukurannya relatif sama seperti mencit (Mus musculus) dengan nilai leukosit 2,483 sel/ $\mathrm{mm}^{3}$ (Pujiastuti et al., 2017), keempat spesies kelelawar memiliki nilai leukosit yang lebih tinggi.

Nilai leukosit pada hewan dipengaruhi oleh stres dan infeksi yang terjadi selama hewan berada dialam liar. Stres yang dimaksud dapat berupa stres fisik dan stres emosional (Khasanah, 2016), namun dalam penelitian ini jenis stres yang dialami kelelawar tidak dapat dideskripsikan dengan jelas. Hal ini dikarenakan nilai diferensial untuk neutrofil tidak muncul dalam hasil pemeriksaan. Nilai neutrofil dapat digunakan untuk dibandingkan dengan nilai limfosit agar indeks stres hewan dapat ditentukan dengan hitungan N/L (Satyaningtijas, 2014).

Berdasarkan data yang didapatkan diduga bahwa individu $T$. nigrescens mengalami infeksi oleh mikroorganisme. Hal ini berkaitan dengan lokasi pengambilan sampel yang berada di tepi pantai dekat dengan aktivitas manusia yang cukup tinggi seperti kegiatan penelitian, ekopariwisata dan aktivitas lainnya. Aktivitas manusia kemungkinan meningkatkan resiko penularan mikroorganisme ke lingkungan tempat hidup kelelawar dan dapat menginfeksi ke dalam tubuh kelelawar ataupun aktivitas manusia secara langsung dapat mempengaruhi nilai leukosit seperti yang dilaporkan oleh Khasanah (2016), yang mengambil kesimpulan bahwa kelelawar yang hidup di gua wisata mengalami peningkatan nilai leukosit karena aktivitas pariwisata.

\section{Eritrosit}

Nilai rata-rata eritrosit spesies $R$. celebensis merupakan yang terendah sedangkan spesies $T$. nigrescens merupakan yang tertinggi. Nilai eritrosit spesies $R$. amplexicaudatus memiliki nilai rataan \pm SD $12,58 \pm 0,93 \times 10^{6} / \mathrm{mm}^{3}$, R. celebensis 11,44 $\pm 1,12 \times 10^{6} / \mathrm{mm}^{3}, T$. nigrescens $13,45 \pm$ $1,52 \times 10^{6} / \mathrm{mm}^{3}$, dan C. luzoniensis 12,82 \pm $0,81 \times 10^{6} / \mathrm{mm}^{3}$ (Gambar 3).

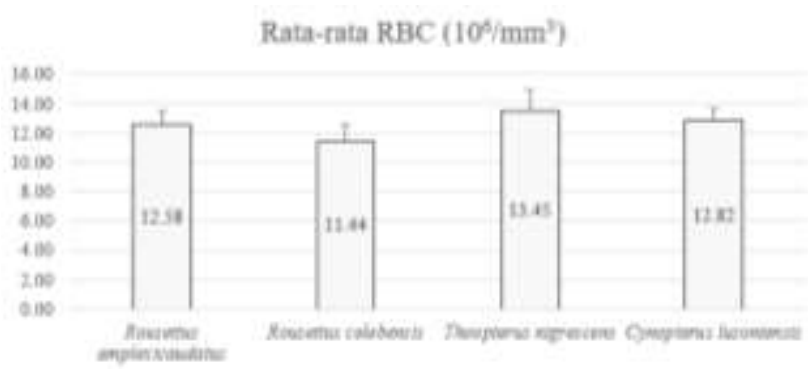

Gambar 3. Rata-rata nilai eritrosit empat spesies kelelawar di Gunung Tangkoko

Nilai eritrosit ini jika dibandingankan dengan manusia berdasarkan rentang nilai bacaan eritrosit tempat pemeriksaan darah yaitu $3,80-5,90 \times 10^{6} / \mathrm{mm}^{3}$, keempat spesies kelelawar memiliki nilai eritrosit jauh lebih tinggi. Nilai eritrosit yang diperoleh jika dibandingkan dengan spesies 
kelelawar lain seperti Rousettus aegyptiacus $12,10 \pm 0,58 \times 10^{6} / \mathrm{mm}^{3}$ (Abdel-Rachied et al., 2014), spesies $R$. amplexicaudatus dan C. luzoniensis relatif lebih tinggi, spesies $R$. celebensis relatif lebih rendah dan spesies $T$. nigrescens lebih tinggi. Nilai eritrosit yang diperoleh jika dibandingkan dengan spesies mamalia yang ukurannya sama seperti mencit (Mus musculus) dengan nilai eritrosit $3,49 \times 10^{6} / \mathrm{mm}^{3}$ (Pujiastuti et al., 2017), keempat spesies kelelawar memiliki nilai eritrosit yang lebih tinggi.

Faktor lingkungan merupakan salah satu faktor yang mempengaruhi jumlah sel darah merah kelelawar. Aktivitas kelelawar sebagian besar terjadi pada malam hari yang memiliki kondisi udara lebih rendah dari keadaan siang hari. Menurut Wijayanti et al. (2011) kondisi udara seperti suhu, kelembaban dan oksigen yang tersedia dapat mempengaruhi jumlah eritrosit dalam darah. Kelembapan yang tinggi, suhu yang rendah dan oksigen yang sedikit dapat meningkatkan kosentrasi hemoglobin (Wijayanti et al., 2011). Peningkatan ini akan sebanding dengan meningkatnya eritrosit dalam darah namun, tetap berkolerasi dengan aktivitas tubuh (Guyton dan Hall, 2008) yaitu aktivitas terbang dan tipe habitat, serta ukuran tubuh kelelawar (Wijayanti et al., 2011). Suhu udara tempat penangkapan kelelawar berkisar antara 20,6 - 29, $1^{\circ} \mathrm{C}$ tergantung ketinggian dan tipe habitat, suhu ini lebih rendah dari suhu siang hari. Pada malam hari tumbuhan juga menggunakan oksigen dalam peristiwa respirasi seluler tanpa atau sedikit menghasilkan oksigen karena kurangnya sumber cahaya yang ada di hutan, sehingga persaingan memperoleh oksigen akan meningkat pada malam hari, sehingga menyebabkan tingginya nilai eritrosit pada kelelawar.

\section{Hemoglobin}

Nilai rata-rata hemoglobin spesies $R$. celebensis merupakan yang terendah sedangkan spesies $R$. amplexicaudatus merupakan yang tertinggi. Nilai hemoglobin spesies $R$. amplexicaudatus memiliki nilai rataan \pm SD $19,70 \pm 1,89 \mathrm{~g} / \mathrm{dl}, R$. celebensis $17,34 \pm 1,56 \mathrm{~g} / \mathrm{dl}$ T. nigrescens $18,16 \pm 2,31$ $\mathrm{g} / \mathrm{dl}$ dan C. luzoniensis 18,60 $\pm 1,54 \mathrm{~g} / \mathrm{dl}$ (Gambar 4).

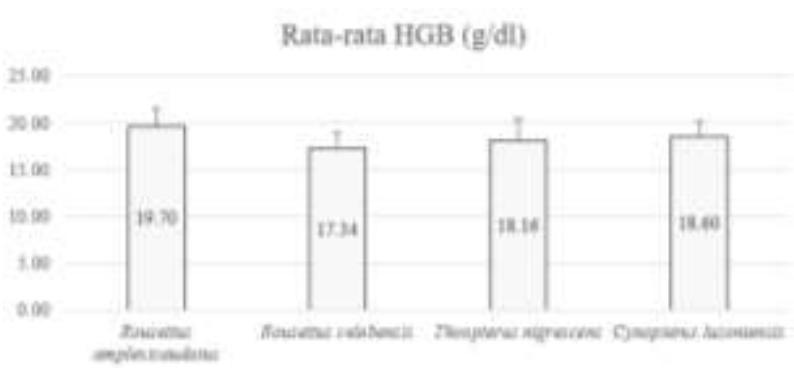

Gambar 4. Rata-rata nilai hemoglobin empat spesies kelelawar di Gunung Tangkoko

Nilai haemoglobin ini jika dibandingankan dengan manusia berdasarkan rentang nilai bacaan hemoglobin tempat pemeriksaan darah yaitu $11,7-1,3 \mathrm{~g} / \mathrm{dl}$, spesies $R$. amplexicaudatus, T. nigrescens, $C$. luzoniensis berada diatas rentang nilai bacaan hemoglobin dan spesies $R$. celebensis berada mendekati nilai bacaan hemoglobin. Jika dibandingkan dengan beberapa spesies kelelawar seperti; Pteropus hypomelanus 15,4 \pm 2,8 g/dl (Heard dan Whittier, 1997) keempat spesies kelelawar memiliki nilai haemoglobin yang lebih tinggi. Nilai hemoglobin yang diperoleh jika dibandingkan dengan mamalia lain dengan ukuran yang relatif sama seperti tikus putih (Rattus norvegicus) $12,00 \pm 0,72 \mathrm{~g} / \mathrm{dl}$ (Ochtavia et al., 2017), burung Puyuh Jepang (Coturnix coturnix japonica) 11,60 g/dl (Setiawan, 2017), keempat spesies 
kelelawar memiliki nilai hematologi yang lebih tinggi.

Nilai hemoglobin memiliki hubungan dengan nilai eritrosit. Kelelawar merupakan hewan nokturnal dan aktivitas terbang yang berbeda dengan cara terbang burung sehingga menyebabkan meningkatnya eritrosit dalam tubuh yang bersamaan dengan meningkatnya nilai hemoglobin dalam darah. Hal ini mengakibatkan adanya perbedaan nilai hemoglobin pada kelelawar dengan burung. Aktivitas terbang kelelawar merupakan aktivitas yang paling banyak memerlukan energi (Maina, 2000; Shen et al., 2010). Sebagai contohnya spesies Pteropus vampyrus mampu terbang sejauh $130 \mathrm{~km}$ selama dua jam (Epstein et al., 2009), sehingga membutuhkan sejumlah besar oksigen dalam metabolisme tubuhnya. Hal ini perlu diimbangi dengan konsentrasi hemoglobin yang tinggi.

\section{Hematokrit}

Nilai rata-rata hematokrit dari spesies $R$. celebensis merupakan yang terendah sedangkan nilai rataan dari spesies $R$. amplexicaudatus merupakan yang tertinggi. Nilai hematokrit spesies $R$. amplexicaudatus memiliki nilai rataan \pm SD $65,70 \pm 5,65 \%$, spesies $R$. celebensis $58,46 \pm 5,05 \%$, spesies T. nigrescens $63,3 \pm 8,97 \%$ dan $C$. luzoniensis 61,76 $\pm 5,36 \%$ (Gambar 5).

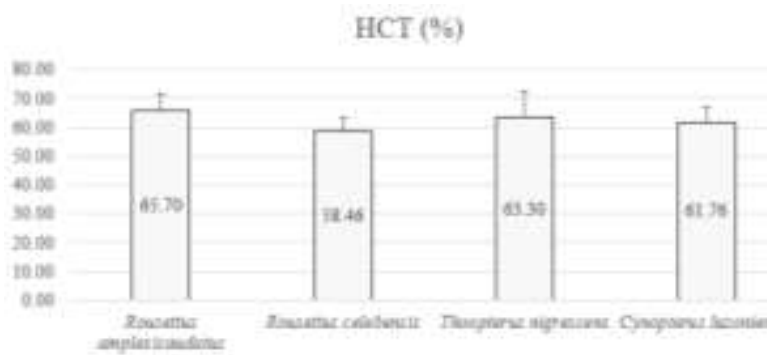

Gambar 5. Rata-rata nilai hematokrit empat spesies kelelawar di Gunung Tangkoko
Nilai hematokrit ini memiliki perbedaan dengan mamalia lain. Jika dibandingkan dengan manusia berdasarkan rentang nilai bacaan hematokrit tempat pemeriksaan darah yaitu 35 - 52\%, keempat spesies kelelawar memiliki nilai yang lebih besar dari rentang bacaan nilai hematokrit manusia. Jika dibandingkan dengan kelelawar lain seperti Rousettus aegyptiacus $50,92 \pm 1.13 \%$ (Korine et al., 1999), keempat spesies kelelawar hasil tangkapan memiliki nilai hematokrit yang lebih tinggi.Nilai hematokrit yang diperoleh jika dibandingkan dengan mamalia lain yang memiliki ukuran tubuh relatif sama tetapi tidak memiliki kemampuan terbang seperti tikus putih (Rattus norvegicus) 40,00 \pm 0,70\% (Fahrimal et al., 2014), keempat spesies kelelawar memiliki nilai hematokrit yang lebih tinggi.

Nilai hematokrit secara langsung berkaitan dengan nilai eritrosit dan konsentrasi hemoglobin. Ketiga komponen darah tersebut memiliki hubungan dengan kemampuan terbang dari kelelawar. Metabolisme yang lebih tinggi pada saat terbang memerlukan nilai hematokrit, konsentrasi hemoglobin, dan nilai eritrosit yang tinggi (Maina, 2000), namun hasil pemeriksaan nilai hematokrit menunjukan tidak adanya korelasi antara nilai hematokrit dan eritrosit dari spesies $T$. nigrescens, $R$. amplexicaudatus, dan C. luzoniensis hal ini berkaitan dengan tingkat keberhasilan pemeriksaan hematokrit yang hanya sekitar 96\% dari nilai sebenarnya (Guyton dan Hall 2008).

\subsection{Platelet}

Nilai rata-rata platelet spesies $R$. amplexicaudatus merupakan nilai yang paling kecil sedangkan spesies T. nigrescens memiliki yang paling besar. Nilai trombosit 
spesies $R$. amplexicaudatus memiliki nilai

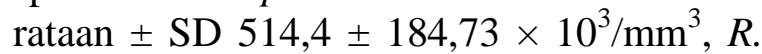
celebensis $659,8 \pm 212,33 \times 10^{3} / \mathrm{mm}^{3}, T$. nigrenscens $975,2 \pm 239,03 \times 10^{3} / \mathrm{mm}^{3}$, dan C. luzoniensis $868,4 \pm 235,03 \times 10^{3} / \mathrm{mm}^{3}$ (Gambar 6).

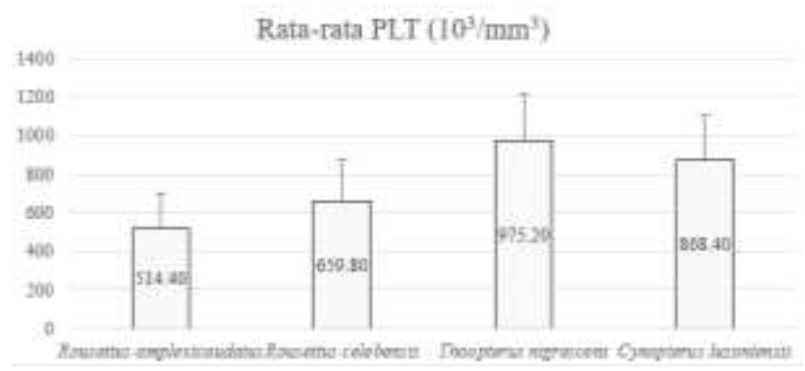

Gambar 6. Rata-rata nilai platelet empat spesies kelelawar di Gunung Tangkoko

Nilai platelet ini berbeda dengan spesies mamalia lain. Jika dibandingkan dengan manusia berdasarkan rentang nilai bacaan platelet tempat pemeriksaan darah yaitu 150 $-450 \times 10^{3} / \mathrm{mm}^{3}$, keempat spesies kelelawar memiliki nilai yang lebih tinggi. Apabila dibandingkan dengan spesies kelelawar lain seperti Pteropus vampyrus 467,80 $\pm 119,24$ $\times 10^{3} / \mu \mathrm{L}$ (Cahyadi et al., 2018) keempat spesies kelelawar memiliki nilai platelet yang lebih tinggi.

Nilai platelet yang diperoleh jika dibandingkan dengan mamalia lain yang ukuran tubuhnya relatif sama seperti mencit (Mus musculus) 129,06 $\pm 18,48 \times 10^{3} / \mathrm{mm}^{3}$ (Widyastuti, 2016) keempat spesies kelelawar memiliki nilai platelet lebih tinggi dari Mus musculus.

Platelet dalam tubuh hewan berfungsi untuk menutup luka dengan mekanisme pembekuan darah (Wolford et al., 2009). Mekanisme pembekuan darah ini merupakan cara hewan untuk melakukan hemostasis dalam mempertahankan aliran darah sehingga darah tidak akan keluar terus menerus dari dalam pembuluh darah
(Hoffbrand, 2006 dalam Masihor et al., 2013), sehingga kemampuan ini pada hewan yang normal mempengaruhi nilai platelet hewan tersebut. Berdasarkan gambar 6 dapat dikatakan bahwa spesies $T$. nigrescens memiliki mekanisme hemostatis pembuluh darah yang lebih baik dari tiga spesies yang lain.

\section{KESIMPULAN}

Nilai hematologi kelelawar yang terjaring di Gunung Tangkoko, yaitu: nilai leukosit yang tinggi pada spesies $T$. nigrescens $\left(28,00 \pm 19,04 \times 10^{3} / \mathrm{mm}^{3}\right)$ dan $C$. luzoniensis $\left(16,24 \pm 9,06 \times 10^{3} / \mathrm{mm}^{3}\right)$ diduga dipengaruhi oleh infeksi berdasarkan nilai limfosit yang tinggi; nilai eritrosit tertinggi pada spesies $T$. nigrescens $(13,45 \pm 1,52 \times$ $\left.10^{6} / \mathrm{mm}^{3}\right)$, dan nilai hemoglobin dan hematokrit tertinggi pada spesies $R$. amplexicaudatus $(19,70 \pm 1,89 \mathrm{~g} / \mathrm{dl}$ dan $65,70 \pm 5,65 \%$ ) dipengaruhi oleh ukuran tubuh dan tipe habitat; nilai platelet/trombosit tertinggi pada spesies $T$. nigrescens $\left(975,2 \pm 239,03 \times 10^{3} / \mathrm{mm}^{3}\right)$ diduga dipengaruhi oleh kemampuan hemostasis pembuluh darah kelelawar.

\section{SARAN}

Beberapa saran yang dapat disampaikan antara lain;

1. Perlu dilakukan penelitian yang sama untuk spesies yang lainnya.

2. Perlu dilakukan penelitian lanjutan mengenai hubungan aktivitas manusia terhadap status kesehatan kelelawar.

3. Perlu dilakukan penelitian lanjutan mengenai sistem kardiovaskuler kelelawar dalam kaitannya dengan 
aktivitas terbang dan nilai hematologi kelelawar.

4. Perlu dilakukan penelitian lanjutan mengenai indeks stres kelelawar.

\section{DAFTAR PUSTAKA}

Abdel-Rachied, H.G., S.A. Zaakhouk, E.I. El-Zawhry, dan Kh. Sh. Elfeky. 2014. Flying or Running Stress Effect on Some Hematological and Biochemical Parameters in Some Birds and Mammals. Journal of Entomology and Zoology Studies 2(2): 153 - 158.

Cahyadi, D.D., Nurhidayat, C. Nisa, Supratikno, S. Novelina, dan H. Setijanto. 2018. Morfofisiologi dan Profil Biokimia Darah Kalong Kapauk (Pteropus vampyrus) dari Wilayah Pesisir Kabupaten Garut. Acta Veterinaria Indonesiana 6(1): $51-59$.

Epstein, J.H., K.J. Olival, J.R.C. Pulliam, C. Smith, dan J. Westrum, T. Hughes, A.P. Dobson, A. Zubaid, S.A. Rahman, M.M. Basir, H.E. Field, dan P. Daszak. 2009. Pteropus vampyrus a Hunted Migratory Species with a Multinational HomeRange and a Need for Regional Management. Journal of Applied Ecology 46: 991 - 1002.

Fahrimal, Y., Eliawardani, A. Rafina, A. Azhar, dan N. Asmilia. 2014. Profil Darah Tikus Putih (Rattus norvegicus) yang diinfeksikan Trypanosoma evansi dan diberikan Ekstrak Kulit Batang Jaloh (Salix tetrasperma Roxb). Jurnal Kedokteran Hewan 8(2): 163 - 168.
Guyton, A.C. dan J.E. Hall. 2008. Buku Ajar Fisiologi Kedokteran. Edisi ke11. Terjemahan A.K. Tengadi. EGC, Jakarta.

Heard, D.J. dan D.A. Whittier. 1997. Hematologic and Plasma Biochemical Values for Three Flying Fox Species (Pteropus sp.). Journal of Zoo and Wildlife Medicine 4(28): $464-470$.

Hossain, M.B., M.N. Islam, A.H. Shaikat, M.G. Yasin, M.M Hassan, S.K.M.A. Islam, A. Rahman, M.A. Mamun, dan S.A. Khan. 2013. Biochemical Profile of Wildcaptured Indian Flying Fox (Pteropus giganteus) in Bangladesh. Jurnal Veteriner Mendicine 11(1): 75 - 79 .

Kementrian Kesehatan RI, 2011. Pedoman Interprestasi Data Klinik. Kementrian Kesehatan Republik Indonesia, Jakarta.

Khasanah, I.U. 2016. Perbandingan Sel Darah Putih Kelelawar Rhinolophus affinis di Gua Alami dan Gua Wisata Kabupaten Gunung Kidul Yogyakarta. Jurnal Biologi 5(6): 10 -14 .

Korine, C., O. Zinder, dan Z. Arad. 1999. Diurnal and Seasonal Changes in Blood Composition of The FreeLiving Egyptian Fruit Bat (Rousettus aegyptiacus). Journal of Comparative Physiology, Biochemical, Systemic, and Environmental Physiology 169: 280 -286 . 
PHARMACON- PROGRAM STUDI FARMASI, FMIPA, UNIVERSITAS SAM RATULANGI,

Volume 8 Nomor 3 Agustus 2019

Lee, R.J., J. Riley, dan R. Merril. 2001. Keanekaragaman Hayati dan Konservasi di Sulawesi Bagian Utara. WCS-IP dan NRM. Jakarta.

Lengkong, H.J. 2017. Diversitas dan Strategi Konservasi Kelelawar di Beberapa Zona Cagar Alam Gunung Duasudara Sulawesi Utara [Disertasi]. Universitas Brawijaya, Malang

Maina, J.N. 2000. What it Takes to Fly: The Structural and Functional Respiratory Refinements in Birds and Bats. Journal of Experimental Biology 203: 3045 - 3064.

Masihor, J.J.G., M.F.J Mantik, M. Memah, dan A.E. Mongan. Hubungan Jumlah Trombosit dan Jumlah Leukosit pada Pasien Anak Demam Berdarah Dengue. Jurnal e-Biomedik 1(1): 391 -395 .

McMichael, L., D. Edson, A. McLaughlin, D. Mayer, S. Kopp, J. Meers, dan H. Fiel. 2015. Haematology and Plasma Biochemistry of Wild Black Flyingfoxes (Pteropus alecto) in Queensland Australia. Jurnal Plos One 10: 1 - 13 .

Ochtavia, Z., N. Asmilia, dan Dasrul. 2017. Kadar Hemoglobin dan Jumlah Eritrosit Tikus Putih (Rattus Norvegicus) Strain Wistar setelah Pemberian Formalin. JIMVET. 1(2): $180-187$.

Pujiastuti, I.N.E., S.R. Lestari, dan A. Gofur. 2017. Gambaran Hematologi Mencit (Mus Musculus) Model
Toksisitas Subkronis. Scripta Biologica 4(2): 75 - 78 .

Satyaningtijas, A.S., N. Kusumorini, M.M. Fachrudin, dan Purnomo. 2014. Profil Leukosit, Diferensial Leukositdan Indeks Stres Luak Jawa (Paradoxurus hermaphroditus). J. veteriner 15(4): 487 - 493.

Setiawan, P., T.R. Saraswati, dan S. M. Mardiati. 2017. Kadar Hemoglobin dan Jumlah Eritrosit Puyuh Jepang (Coturnix Coturnix Japonica L.) setelah Pemberian Tepung Kunyit (Curcuma longa L.) dan Tepung Ikan dalam Pakan. Jurnal Pro-Life 4(2): 339 - 346 . 